\title{
Indice generale
}

Premessa — VII

Introduzione - 1

Antefatti - 1

Attribuzioni paleografiche -2

Studi testuali $\_\mathbf{4}$

I Su Isacco Argiro - 6

I.1 Fonti librarie e documentarie - 6

I.2 Attribuzioni -9

II La scrittura di Isacco Argiro - 12

II.1 Il panorama grafico del XIV secolo: questioni di metodo - $\mathbf{1 2}$

II.2 La scrittura di Argiro: caratteristiche e modelli $-\mathbf{1 4}$

II.3 La scrittura di Argiro: una descrizione analitica — 29

III Collaboratori di Isacco Argiro - 44

III.1 Nota introduttiva -44

III.2 Copisti dei codici di argomento profano - 45

III.3 Copisti dei libri di argomento teologico-dottrinario - $\mathbf{5 2}$

III.3a Scritture di tipo geometrico -52

III.3b Scritture di tipo rotondo -60

III.4 Collaboratori identificati -61

IV Ancora sui collaboratori di Isacco Argiro: numerose mani simili -68

IV.1 Anonimo G? -68

IV.2 Anonimo $A-72$

IV.3 Anonimo $B-76$

V L'erudito e i suoi libri -79

V.1 Tipologie testuali -79

V.2 I libri e il cursus studiorum $\mathbf{-} \mathbf{8 0}$

VI Argiro e la controversia palamitica - 98

VI.1 Gli opuscoli teologici di Argiro - 98

VI.2 Strumenti e metodi dell'elaborazione letteraria — 99

VII Una cronologia relativa dei manoscritti di Argiro - 119 
$\mathbf{X}$ - Indice generale

Epilogo - 128

Schede dei manoscritti -129

Tavole -265

Bibliografia -267

Indice dei nomi -295

Indice dei copisti anonimi -299

Indice delle testimonianze manoscritte e a stampa - 301 